\title{
Making Recruitment and Selection Tools to Solve the Lack of Human Resources in Benchmark Company
}

\author{
Bella Halim \\ English Department, Faculty of Languages and Literature, Petra Christian University, Siwalankerto 121- \\ 131, Surabaya 60236, INDONESIA \\ Email: rebellahalim@gmail.com
}

\begin{abstract}
Benchmark is the parent company of Basha Market and Of Sorts. The main problem of Benchmark is a lack of human resources. In their new organizational structure, there are still seven vacant positions in their three departments. New qualified employees are needed to fill these positions. In order to do that, recruitment and selection tools are needed. The first tool, the recruitment tools, can help Benchmark attract the right people for the jobs. They consist of job advertisements and an application form. The second tool, the selection tools, can help the company screen the candidates to finally pick the best people to work for them. The tools consist of a pre-interview questionnaire and the an interview question sheet. With all the tools, Benchmark can select the right candidates and expected to be able to function as an effective and efficient company to deal with future challenges.
\end{abstract}

Keywords: Hiring, Recruitment, Selection, Human Resources, Job Description.

\section{INTRODUCTION}

In August 2018 until November 2018, I did my internship in Basha Market. Sometimes, I also did the workload from Of Sorts as those two companies are owned by the same people. Basha Market is a project built by Erin Christie and Devina Sugono in 2015. Taking a form as an indoor thematic-bazaar, it is a place made for Indonesian with a start-up business to interact, introduce their product to people, and make sales. Being the pioneer of the creative-industry market in Surabaya, Basha Market emphasizes on its authentic theme and design, making it successful as people are interested in the experience of thematic ambiance. On the other hand, Of Sorts is a newer-established company (back in 2016) which is a branding company. Concentrating on each brand's story, concept, and design, Of Sorts—just like Basha Market—puts a strong emphasis on its design. Of Sorts specialties are experiential marketing, digital content, influencer engagement, and identity branding. Their clients vary from big companies like Go-Jek, Shopee, and Sanrio, to smaller start-up businesses (usually creative industries) like Luna Luna Collection and Daruma.

These two companies are operating under the name of Benchmark, a bigger company name. In short, Benchmark is the mother company while Basha Market and Of Sorts are its subsidiary companies. In November 2016, Benchmark, along with Basha Market and Of Sorts under it, became a limited liability company under the name of PT. Untuk Jalan Jalan Terus with Laurensia Handriani as the person in charge.

They have two headquarters, an office in Jakarta and Surabaya. They do not have exact working hours. The people working there come and go depending on the works they need to do. As it is a project-based work, sometimes the office hours is longer than the normal office working hours. A lot of times they work outside the office as well. However, for me, the internship schedule is from 10 am to 5 pm ideally (sometimes I worked overtime or went home earlier, depending on the workload on that day). 
Talking about the Basha Market itself, after the success of the project in Surabaya, a lot of people saw this creative market industry as a business with a huge opportunity with a high profitability. Only take less than a year, the creative industry market was becoming a very common thing in Surabaya, even until now. At first, I thought this newborn market (for example Project X, Kepo Market, Headquarter) phenomenon can be considered as a challenge for Basha Market. When Basha Market still focused on its themes, vendors, and workshops, these new competitors updated their market for not just selling and buying, but spice it up with competitions, guest stars, music, talk shows, and any other interesting activities. However, contrary to my belief, Basha still stands tall. Ignoring all the competitors' step on adding many activities to their markets, Basha Market still holds its value: a high-quality market with a high rate of price, targeting middle to upperclass Surabaya people. The vendors joining them are the well-known local authentic brands. They strictly select the brand that can open a booth in Basha. They specifically target heavy shopper and influencer to come to Basha, as these people usually shop a lot. When the competitors concern about the number of people coming, Basha concerns on its qualities and sell-count. They keep their class with an enjoyable ambiance with designs that can be experienced freely by varied class of people. Basha's main concern lays on the sales and educating people to appreciate local creative industries in Indonesia, as their main vision is to bring Indonesia's creative industry to the global market. Digging further to the marketing and branding of Basha, it is safe to say that they have no problem on marketing and branding. It is also assured that the other company, Of Sorts, also has no problem regarding their marketing and branding as they always have non-stop projects and clients, even rejecting some of the new clients.

Talking about the company's structure, Benchmark was a small company with a small team. At first, Benchmark only had five people as the brain of the projects and branding. The old organizational structure worked well on Benchmark on its early days. However, as the company grew bigger, the old organizational structure and number of employees did not fit the company's need anymore. The company lacked human resources. The lack of workers made the work division not really structured or even can be called odd jobs. Each person in the company had to do things outside theirs. This situation made them do whatever job available (especially on the Dday of the events for Basha). It was really problematic when the workloads of Of Sorts was too much to handle that they finally rejected some of the new clients. The directors themselves admitted that they could not think about the future of the company and brainstormed some new ideas because their time are wasted on meeting people (mostly), supervised the workers on the warehouse, or simply did their financial reports. These problems led to many other problems. The current employees were sometimes get pressured as the workloads were usually too sudden and seemed to be impossible. If the company wanted to be more developed, the director's time is needed to think about business development.

Figured out the problems, the directors finally made a new organizational structure and hired some new employees. After the upgrade, Benchmark had nine employees. The upgraded organizational structure was quite a progress for Benchmark. However, as it can be seen on the new structure, some positions are still empty, even until now. The new organizational structure could not work properly if the positions are still empty. The workloads in the company are still bigger than the number of current workers. Even the condition is better with nine people, the company still lacked human resources.

The solution to this problem is to do a recruitment and selection process for Benchmark. In short, the meaning of the process here is to figure out the job description based on the new positions on the organizational structure, design the job advertisement, spread the job advertisement, do candidate screening, and finally hire new people to fill the positions. This whole process requires some necessary tools to support it, so the recruitment and selection process can really attract the right people to be Benchmark's new employees. The recruitment and selection tools are the goals 
of this BCFP project. The tools will help the recruitment and selection process for now and can be reused as well in the future when Benchmark needs new people again.

\section{METHODOLOGY}

To execute the Business Communication Final Project, there are sets of procedures that have to be completed before, during, and after doing the project. The following are the procedures that were completed in making the recruitment and selection tools for Benchmark company. After finishing my internship, I had a conversation with Benchmark's Director about the problem inside the company. It turned out that the company problem is the lack of human resources and they want new people as soon as possible. Next, I made a proposal in which I discussed the problems I found at Benchmark Company which related to its empty slots on its new organizational structure. I consulted my advisor whether this is a problem related to the Business Communication field or not, and asked if it is possible to solve this problem by making a Business Communication Tool. He approved that it is a Business Communication tool due to the function of the tool that communicates employment and applicants' standards. After I got the approval from my internship advisor, I made the project proposal. Along the way, I always consult my progress of the proposal and project to my thesis advisor. Lastly, I present the proposal to the Board of Examiners. This leads to the permission of doing this Recruitment and Selection Tools as my BCFP project.

There are several steps that I did to get the approval from Benchmark regarding this project. Firstly, I arranged a meeting with one of the directors. Here, I discussed the company's problem with her. Together, we were looking for the solution for the lack of human resources that we found out. She told me everything that she needed in the company, and I also gave her some suggestions regarding this problem. She made a rough sketch for the new organizational structure, and figure out the new positions needed. Finally, I carried all the information. Next, I made the formal company proposal for Benchmark, since it was required to do so. I made the proposal and arranged one more meeting with the director to discuss the proposal, alongside with every project's rough drafts that I had made. Here, I discussed the changes and suggestions from my advisor regarding the tools. I added the application form, the pre-interview questionnaire, and the interview questions, so I communicated the addition to the director. Benchmark accepted the addition and the proposal, signing the contract as well. That is how I get the company's approval of the BCFP project.

To do the project, there were several steps that I followed. First, I gathered some information about the job position needed by interviewing one of the directors. I took notes and asked her about the general knowledge about the position. Next, I did some research through books and online articles about each tool: 6 Job Advertisements, including job descriptions, 1 Application Form, 1 Pre-Interview Questionnaire, and 1 Interview Question Sheet. For the job advertisement, I did research on the detailed workloads each position needs, as well as the criteria needed for each position. For the other tools, I made a summary from different resources, picked the best that fits the company's condition. After getting all the pieces of information, I started drafting the hiring tools. It was still a rough draft, yet I made it as complete as possible. I consulted the rough draft to the directors. This includes the job description, interview question sheet, pre-interview questionnaire, and application form. I created these based on the theories from the books and online articles that I read, and also my advisor's suggestions. In the job description, I put mainly the job title, the main tasks and responsibilities, and the location. I made it as simple as possible as the job description will be spread among young people more through social media, especially Instagram. In the job advertisement, I put mainly the job description and the person specification. Other than that would be Benchmark's logo, the working place, and the contact information of Benchmark. In the interview questions and questionnaire, I wrote the rough questions on a document, based on articles and suggestions from the advisor. After getting the approval, I started 
designing the tools, then consulted the final result to the directors. I did a minor revision of the designs. Finally, I gave the tools to the directors in a digital format.

\section{FINDINGS AND DISCUSSION}

Since Benchmark does not have a human resources department yet, the tools are meant to be used by the directors to recruit new people. These tools are the "guideline" for them to execute the process of recruitment and selection in near time. Later, the tool can be used again (except for the job advertisement) when they do another batch of recruitment and selection in the future.

All the tools are made in English as English is being used a lot in Benchmark. Their designs and guidelines for their clients are all in English. This is mainly because one of Benchmark's goal is to bring the local products to International market, which uses English as the international language. Other than that, Benchmark's creative inspiration usually based on international media to broaden the company's view.

The job description contains several parts. The first part is Benchmark's logo. It is there to show the people which company is opening recruitment. The second part is the text "WE'RE HIRING!" It is there to show what the content of the advertisement is about. The text's font is bigger and different than the other as it is basically the title of the advertisement. The third part is the text "JAKARTA" and "SURABAYA" It is obvious that it is the location where the employees will be placed. In Benchmark's case, the new employees can be placed either in Jakarta or Surabaya, based on the later agreement with the directors. The fourth part is the job title. It is to identify what position is available. The fifth part is the job description and person specification. Here is written the job that the position will do daily. This part contains the responsibility and workloads for the position. It also contains the information about what kind of person is needed for the job: specialties needed, the personality that fits, age, and some portfolio. As the target is mostly young people, the job description and person specification written there is short and concise, but clear enough to be understood by the target. This is meant to avoid boring details. The sixth part is the contact information. Here is written the director's email address to be contacted if applicants need further information. The applicants also send their CV to this email as well. The job advertisements are designed in 1080x1920 pixels; the pixel of Instagram's story.The first tool, the job advertisements, are made to help Benchmark spread the recruitment news throughout its targets. As the tool is meant to be put in Instagram story, the Instagram story itself is a feature made by Instagram, allowing its user to post picture or video that disappear in 24 hours. After an update, the Instagram story can be put in a feature named "Highlights" that will be shown under the profile of each user. The user can name the highlights so that the people visiting one's profile can figure out what the highlight is about and open the set of highlights "album" which they like. This is actually a nice feature as people love looking at Instagram stories because of its simpleness. It also would not ruin the aesthetic regular Instagram post feed that a visually creative company always keep. Other than that reason, the biggest reason to use the feature is that Instagram is currently Benchmark's best social media platform with approximately 31.500 followers on Basha Market's account and 1.432 followers on Of Sorts account. The huge number of followers is a huge benefit for Benchmark to spread the job advertisements. As the followers of both accounts are people interested in creative industries and designs, it is most likely that the job advertisements will get advertised to the right target right away through Instagram. Advertisement through social media (mainly Instagram) is really effective, easy to look at, and easy to spread (it can be spread through accounts like @lowongankerjasurabaya or @ loker_surabaya). If Instagram is not enough, Benchmark can still use the job description to be posted in job-searching websites like job street or karir.com. They also can print the design into a poster and spread it to universities as their target are also fresh graduates (this one requires more 
time, so if they want to, I will be the one that does it, just like what I mentioned in the company proposal.)

Writing the job descriptions and person specification, I use a book reference titled "Job Description Compendium" written by Eleni Kourmentza. There, the author gives a lot of job description for many jobs, along with the person specification. I took a look of it and found six job description that fits Benchmark's need, then revise it to make it more concise and fit Benchmark's identity (the language, the works, etc). The job descriptions from the book that are being used in the tool are Senior Accountant, Project Manager, Public Relations Manager, Editor, Graphic Designer, and Marketing Manager. Even if the job title from the book is different from Benchmark's, the workloads that the employees will do are similar, so I decided that it is right to use the information of job decriptions from the book.

The application form is made to be filled by the applicants once they apply for the job position. As the application form is a tool to enable the recruiters to get the idea about the applicants, it contains several parts. The first part is personal information. This part is the most general of all. It contains the very basic information of the applicants as a citizen and the contact information of the applicants. The applicants are obligated to fill their full name, position that they applied for, sex, marital status, number of children, birth date, address, phone number, and email address. The second part is Educational Background. This part contains the education that the applicants have gone through in the past. This part only emphasizes education from high school, college/univ, and graduate education (if any). They also need to put their GPA there, especially in the case that the applicants are fresh graduates. It is at least one of the most objective and easy way to determine one's quality, before looking at their resume and pre-interview questionnaire answer. The third part is experiences. This part should be filled if the applicants have ever worked in the past before. They need to fill in the employer, field, and their working period. This can give a general idea about the person's experiences in several fields. If the applicants do not have any working experience, they can leave the part blank. The fourth part is checklist. This part is the part that shows what documents the applicants need to submit in order to apply for the job. Here, they need to give their curriculum vitae, photo of identity card, latest photo, graduation certificate, transcript, and optional portfolio. These formalities can help the recruiters ensure whether the applicants are a legal citizen with a clear background. The application gives very basic information about the applicants. This tool is necessary to screen the candidates and pick the best with the most fitted general information. The application form also contains the logo of Benchmark to show that it is theirs, and the title "New Employee Form" to give the idea about what the whole sheet is about. As it is meant to be filled with words, I keep the design simple to avoid distractions. The application form is made to be filled by the applicants. Because of its function to give the director idea about the general qualities of the candidate, I recommend it to be sent to the applicants' mail after they send their CV to Benchmark's email, together with the pre-interview questionnaire, in PDF format. The applicants can download the file, print it out, fill it, scan it or edit it (writing the answers), and send it back to Benchmark for further process. It is a more effective way to fill it rather than asking the candidates to come to Benchmark's office. This way, the director's time can be saved because all of the processes so far is done online.

The pre-interview questionnaire (the pre-screening interview) is that tool made to give the recruiters general idea about the applicant's personality and personal preference. The tool can help the recruiters determine whether the applicant fits the job they are applying for or not. The preinterview questionnaire is basically sheets which contain questions to be answered.The third tool, the pre-interview questionnaire, is basically used just like the application form. Meant to screen the applicants' personality and preference, the tool is the best to be given to the applicants online, in PDF format, together with the application form. They will fill it and send it back to Benchmark. It is quite effective, the directors do not have to waste their time meeting a lot of people, and they can judge the coming applications as much time as they need (they do not have much time). Next, 
Benchmark can select the best candidates to meet them in one on one interview afterwards. Based on the explanation on each job position and the details of the personality needed, there are most important sections to look at on each position. First, for the Senior Accountant the first most important quality is neatness and details, and the second most important is resilience. To be able to work in an office in an exact amount of time, face on laptops and financial data, a high score in neatness and details is needed. To be able to keep up with the schedules and the same thing every day, resilience is also needed. To count and to make the financial report, the eye of detail surely is needed to avoid wrong input and misunderstatement. Second, the Junior Project Manager needs resilience and teamwork. The junior project manager position is not much difference with the senior project manager. As their job is basically executed all the production process of main events, resilience is needed. This department is probably the busiest department in Benchmark. On the preparation of the event days, they have to supervise everything, from the properties to the vendors. Great teamwork is also needed because this position will work with a lot of people from outside Benchmark. This position also works with the content department as the project managers are the one turning the content's team idea to reality. Third, the Public Relations Coordinator needs communicativeness and creativity. This position requires very good communication skill as the job requires meeting clients, partners, media, and sponsors. He/she should be able to be a good representation of Benchmark and keep its name standing tall. A high skilled communicator sure is needed here. Not just that, maintaining public images and media requires deep creativity to be able to produce a unique way to engage with Benchmark's audience. Fourth, the Junior Editor needs creativity and, neatness and details. The junior editor needs high creativity as the position responsible mainly in Basha.id, a creative platform. The main job description is content creating, and to be able to do so, a person with a creative mind is needed. Neatness and details are also needed due to the fact that he/she has to sit for a long period of time and create contents (mostly writings) in details. Fifth, the Junior Graphic Designer needs creativity and resilience. The junior graphic designer should have the creativity to translate the clients' and the content director's vision into visual designs. Because of this, creativity (and experience in the creative field) is needed. Moreover, it is not a secret anymore that the graphic designer has to do endless revision; the one doing it should have quite a resilience. Sixth, the Marketing Coordinator needs communicativeness and creativity. Communicativeness is the key to be a great marketing coordinator. As the main responsibility is to communicate and sell Benchmark's brand to a bigger market, strong communication skill and confidence is needed. Not just that, this position also requires creativity as he/she needs to brainstorm creative marketing ideas. Seventh, the Conceptor needs creativity and communicativeness. Conceptor is the brain, the core of all projects and events. $\mathrm{He} / \mathrm{she}$ has to think outside the box, spilling ideas into paper and communicate it to the team. The main job of this position is brainstorming ideas every time, and it would not be nice if he/she runs out of it. Because of this, a brilliant creative mind that has tons of ideas is a necessity. The communication skill is also needed as the concept needs to present his/her ideas to the team that will execute it into reality.

Before going to the questions, there is the title "Pre-Interview Questionnaire" to show what the document is all about. There are also places for the applicants to write down their name and the job that they are applying for. Next, there is an instruction for the first part of the questionnaire. The first part is the circling part. In this part, the applicants need to circle the best answer to their condition and preference regarding the questions. The first part of the questionnaire is divided into sections. The section is based on the top five personalities and qualities that are needed to survive in this busy company. I determine the personalities based on the observation when I had an internship in the company. These five personalities and qualities are cooperation/teamwork, resilience, communicativeness, eye for details, and creativity. As for now, Benchmark opens 7 job positions. Some jobs share the same personalities and qualities needed for the job. For the section 1, Cooperation/Teamwork which are question A to E, mainly asked about the applicants thought and action towards teamwork. The ability to work in a team is important for Benchmark as they are still a growing company with a small team. Every individual is important and 
significant enough to make things work well. Section 2, Resilience, which are question F to J, mainly asked about the applicant's qualities on his/her resilience (deadlines, overtime works, etc). Working on Benchmark can be overwhelming sometimes, especially when the due date of an event is near, or when all the workloads come together. This is why a strong person with durability is needed in Benchmark. Section 3, Communicativeness, which are question $\mathrm{K}$ to $\mathrm{O}$, mainly asked about the applicant's thought about working in a field that requires communication a lot, as well as their capabilities in communication. In Benchmark, this skill is strongly needed as each employee always need to present their ideas, communicate the production's result, or communicate through social media. Each person should have this ability to tell the others about what is going on inside their head, and to communicate with clients, vendors, and outsource workers. Section 4, Neatness and Details which are question P to T, mainly asked about the applicant's preference of work style and their eye for details. To work inside an office from 10 to 5 , and mainly in front of the computer for some jobs, the ability to sit and do office-like works is mostly needed. As for the eye of details, it is needed as Benchmark is a creative/branding company. Every little piece of details should be reck to build the big picture. Section 5, Creativity which are question $\mathrm{U}$ to $\mathrm{Y}$, mainly asked about the preference and experience of the applicants to work in a creative field. Benchmark obviously is a company that creates creative images, as its main emphasis on each project are design, stories, and identity. Creative minds are needed to produce fresh ideas for every client and event. It is safe to say that creativity is the core of Benchmark, and it is the most needed quality for the employees. All the criteria sure are important in Benchmark. Yet, to look at all of the 25 answers and score it all requires much work and time. To make it simpler yet still accurate, the directors just need to look at the two most important personalities each position need and score just the two of it. The way to score the questionnaire is simple. The directors just need to sum up all the numbers circled by the applicants, to determine how strong their qualities in each sections is I write sections' headings to make it easier for the directors to just mainly look at the answer from the qualities needed for the position applied (I tell them the parts that are need to be recked more on each job position). It is more effective way rather than to put it in separate piece of paper that is prone to be forgotten. This too, is done to avoid confusion looking at separate piece of paper. It does not change the way the applicants fill the form too, so it is the best to put the section heading there. The second part of the questionnaire is the writing part. The instruction is to write down the applicants idea about Benchmark and the job that they will do. This section is basically meant to see whether the applicants really understand their choice of work, as well as general understanding of the company. This also can be a test for the applicant's writing capabilities, especially in English. The last part is the salutation and blank. It is the place for the applicants to sign the questionnaire and put their name below it.

The interview questions sheet contains the general questions that are meant to be asked in one on one interview. There are several parts of this tool. First, there is a Benchmark logo, as usual, to make it clear about who is owning that sheet. Second, there are the title "Interview Questions" to give the idea about what the sheet is about. Third, there are some blanks to be filled by the interviewer: the name of the interviewee, the position applied, date of the interview, time of the interview, and where the interview took place, just mainly to refresh the memory when the directors need to look back at it. There are 12 general interview questions that are the basic guideline for the interview process. After each question, a blank space is given for the note-taking purpose. The design of the tool is kept simple because of the needs of taking notes. It is as well to avoid distractions. The fourth tool, the interview question sheet, is the only tool that should be used when they meet the applicants. Because the tool is basically a guide for the interview, it is meant to be printed and brought to the interview. The directors can fill in the interviewee's information on the blanks, and write down the interviewee's answer concisely under each question. If there are impromptu questions, the interviewers can still use the blanks in the sheet to write those down as well. After the interview, when they need to compare the candidates, the notes on the interview question sheet can be a helpful guide for them to decide the final outcome objectively. The questions in the interview question sheet are the traditional questions. I use 
traditional questions because of the theory of the advantages of traditional interview questions. I look for the questions online and found out that the general questions are all about the same. The questions like "tell me about yourself", "what are your biggest strengths", "why do you want to work here", etc, might reveal the candidate's personality, as well as their view towards the job and expectations in general (as the interview time is always limited).

The recruitment tools can be considered successful when it can attract numbers of qualified people to apply for job positions. The selection tool can be considered successful when it can select and pick the best of the best applicants to work at the company. The success meter can be shown later when the tools are started to be used.

\section{CONCLUSION}

The main problem that Benchmark faces currently is the lack of human resources. Both of Benchmark's subsidiary companies, Basha Market and Of Sorts are run by the same nine people. There are still seven vacant positions in their organizational structure. The solution to this condition is to find the right people to fill the empty positions on Benchmark. In order to attract and select qualified people, some tools are needed to support the process. Since Benchmark does not have such tools, I made it for them to ease Benchmark's process of recruitment and selection. The recruitment tools are seven job advertisements and an application form. The selection tools are a pre-interview questionnaire and an interview question sheet. The recruitment and selection tools are expected to be helpful for the company. The directors can use the tools to attract and pick the right people for the needed positions. Later, the tools (except for the job advertisement) can be used again when they need new employees in the future. This will ease the directors and give them efficiency in time as the tools will help them with the long process. Furthermore, when they have the right people working for them, Benchmark can become a more effective and efficient company to deal with future challenges. My suggestion for the company to make the most of the tool are to truly understand the content of the tool. The company has to know what the mandatory qualities that they need, the meaning of the questions asked in the forms and interview, and the technique of scoring the candidates. The tools also need to be used through the right media, which is mostly the digital media, at the right time. The people using these tools should fully understand how to use it. However, above the tools, the most important thing to get the right people working for the company is not looking at the best people, but the most suitable people. In this era, it is not hard to get the extra-qualified people, yet, it is more important to get the people that have the same vision and spirit as the company, and willing to be a lifetime-learner.

\section{REFERENCES}

Kourmentza, E. (2014). Job Description Compendium. Boston: Workable. 